\title{
Semantics of Slavic anaphoric possessive determiners
}

\author{
Richard Zuber \\ Radié des cadres du CNRS, Paris
}

\section{Introduction}

In this paper I analyse expressions, found for instance in Slavic languages, which traditional linguists called possessive pronouns, possessive adjectives or, sometimes anaphoric pronouns. These denominations correspond to the fact that the expressions in question involve the relation of possession on the one hand and the relation of co-referentiality, in a broad sense, with a nominal antecedent on the other. Their adjectival character, however, is less obvious. It is true that they apply basically to common nouns but it is not true that they play the role of modifiers in such an application. As the result of their application to a common noun we obtain expressions which in many respects are like noun phrases. More precisely, expressions thus obtained occur in the simplest case on object position and play the role of nominal anaphors whose interpretation depends on the interpretation of the corresponding subject noun phrase, which is thus its antecedent. For these reasons I call them anaphoric possessive determiners or just anaphoric determiners.

The basic anaphoric determiner I will analyse is a member of the class SVOJ to which belong various lexical items found in most Slavic languages, with their various morphological forms often phonologically similar across various Slavic languages. It will be glossed by HOWN, meaning roughly his/her own (as in Bill likes not only his own children). I will not try, however, to point out any similarity or difference between his/her own in English and anaphoric determiners to be discussed.

I will analyse essentially some semantic aspects of the Polish anaphoric determiner swój including some of its morphological forms and lexical compounds. Results obtained here for the Polish determiner swój supposedly extend to similar items in other Slavic languages or even to similar items in non-Slavic languages. Not much will be said about these comparative matters.

As we will see, the semantic description of the anaphoric determiner that will be proposed concerns not only the bare determiner swój itself but various compound determiners which are formed with it. Among such compound determiners we will consider two types, syntactically distinct: unary, that is those taking one common noun as argument, and binary, with two common nouns as arguments.

It follows from this that, in addition to providing a semantic description of various constructions which will necessarily involve some aspects of anaphoricity, I will also be interested in some other formal properties known from the study of determiners and anaphors in general. Concerning the anaphoric character of the

No particular thanks except maybe to Ross for the help with English. 
Slavic anaphoric determiner we will be led to extend the notion of anaphoric function introduced by Keenan (Keenan (2007)) who analyses semantic properties of nominal anaphors. Such anaphors denote functions which are reducers of arity of relations. In particular for the case of nominal anaphors in object position these anaphors denote functions from binary relations (denotations of transitive phrases) to sets (denotations of intransitive phrases). These functions are different from functions denoted by "ordinary" noun phrases. For our analysis we will extend the notion of an anaphoric function to functions denoted by anaphoric, unary and binary, determiners. These functions will take a set and a binary relation as arguments in the case of unary determiners and two sets and a binary relation in the case of binary determiners. In both cases they give sets as results.

Furthermore, I will also be interested in a generalisation of the notion of conservativity. The reason for this is related to the fact that compound anaphoric determiners obtained from the anaphoric determiner swój contain also "ordinary" (nominal) determiners as their syntactic parts. The classical notion of conservativity applies to such ordinary determiners but not to anaphoric determiners because, roughly, they cannot occur in noun phrases in subject position. Given, however, their structure, that is the fact that they are systematically related to ordinary determiners, it seems reasonably to inquiry about their (generalised) conservativity. This will be done in section 5 following section 4 devoted to the description of anaphoric properties. The presentation of formal properties discussed in section 4 and 5 is based on an unpublished paper of mine "Constraints on anaphoric functions"

\section{Data}

Polish has three grammatical genders. The determiner swój is of masculine gender. Its feminine form is swoja, neuter gender and plural is swoje. These forms, as presented, are in the nominative case. However, since the noun phrases formed with the help of these determiners cannot occur in subject position, which is the only position necessitating nominative case, in practice these forms are never used. Instead forms corresponding to the accusative, or sometimes other grammatical case, are used. Incidentally in Polish there are two accusative forms corresponding to the nominative swoj: these are swego and swojego. There does not seem to be a semantic difference between these two different forms.

Let me present now various empirical facts concerning the determiner swój or complex determiners containing swój in Polish. As already indicated, syntactically noun phrases formed with anaphoric determiners cannot occur on subject position (except maybe in some generic sentences or some frozen expressions) and consequently they are not used in the nominative case. For related reasons sentences with such anaphoric direct objects cannot be passivised.

Similarly, and this is a basic observation for the semantics of anaphoric determiners, the noun phrases they form with common nouns are anaphorically related to or are bound by subject noun phrases in the same sentence. They cannot be bound 
by other noun phrases occurring in the sentence.In other words subject noun phrases play the role of antecedents for anaphors formed with anaphoric determiners. In addition the subject noun phrases bounding them must be in the nominative case. In particular they cannot be dative subjects, that is subject noun phrases marked by the dative case (such subjects exist with some specific verbs in Polish). This is shown in the following examples:

(1) Kazio pokazał Piotrowi swój rower.

Kazio showed Piotr HOWN bicycle

'Kazio showed to Piotr his (Kazio’s) bicycle'

(2) Kaziowi podobają się * * swoje/jego obrazy.

Kazio please refl-part HOWN/his paintings

'Kazio likes *his own/his paintings'

The grammatical status of such constructions changes when the anaphoric determiner is modified by the intensifier wlasny 'own'. Thus (3) is more acceptable than (2):

(3) Kaziowi podobają się swoje własne obrazy

Kazio please refl-part HOWN own paintings

'Kazio likes his own paintings'

Given the above facts, one also notices that the anaphoric determiner swój is opposed to possessive non-anaphoric pronoun jego his, in the same way as himself is opposed to him in English. Consider the following examples:

a. Piotr nienawidzi swego sa̧siada

Piotr hates HOWN neighbour

'Piotr hates his neighbour'

b. Piotr nienawidzi jego sassiada

Piotr hates his neighbour

'Piotr hates his neighbour'

In (4a) the neighbour hated is necessarily Piotr's neighbour whereas in (4b) it cannot be Piotr's neighbour.

Though noun phrases formed with swój or with complex determiners containing swój cannot play the role of the subject they can occur in any other position on which ordinary noun phrase can occur, not only in the position of direct object. Since direct objects in Polish can often be marked by a non-accusative case anaphoric noun phrases containing swój can be marked not only by the accusative case but also other cases. In addition one can have more than one such anaphoric noun phrase in the same sentence and consequently the subject noun phrases can serve as anaphoric antecedents for many anaphors. Thus we have:

(5) Piotr przyleciał swoim samolotem.

Piotr came-by-flying HOWN aircraft

'Piotr arrived on his own aircraft' 
(6) Kazio nigdy nie spotkał swojej żony.

Kazio never not met HOWN wife

'Kazio never met his (own) wife'

(7) Kazio pokazał swojej dziewczynie swój rower .

Kazio showed HOWN girl HOWN bicycle

'Kazio showed his girlfriend his bicycle'

A related property of noun phrases formed with the anaphoric determiner swój is that they cannot function as predicates. More precisely they cannot occur without restriction in copulative verb phrases or as bare verb phrases. In addition, given the anaphoric nature of swój, the antecedent of the anaphora must be present in the sentence. These facts are illustrated in the following examples:

a. Jan powiedział że to sa̧ *swoje/jego książki.

Jan said that this are HOWN/his books

'Jan said that these are *his own/his books'

b. *To sa̧ swoje książki.

This are HOWN books

‘*These are one's own books'

As the next example shows in order for an anaphoric noun phrase formed with an anaphoric determiner to occur in a copulative predicate it must be "completed" by the intensifier wtasny 'own':

a. ?On został swoim lekarzem.

$\mathrm{He}$ became HOWN doctor

'*He became his doctor'

b. On został swoim własnym lekarzem.

He became HOWN own doctor

'He became his own doctor'

The above facts suggest that bare swój is not an adjectival modifier. When completed by the intensifier wtasny 'own' the result is closer to an adjectival phrase. Observe in addition that there are no comparative or superlative forms of swój, even in a very metaphorical reading.

In spite of their possessive character, Slavic anaphoric determiners apply to "simple" common nouns and relative common nouns (like neighbour for instance) without noticeable distinction.

Finally, the determiners in question can be modified by wtasny 'own'. Thus in addition to swoje dzieci 'OWN children' one has swoje własne dzieci 'one's own children'. The semantic or pragmatic effect of such a modification has something to do with focus or emphasis as it is often the case with anaphors. We will not discuss this problem in any detail.

Up to now we presented a series of empirical facts concerning bare anaphoric determiner swój. An important empirical observation concerning swój in Polish is 
that this determiner can combine with virtually any non-anaphoric unary or binary determiner to form a complex determiner which, when applied to a common noun, gives a nominal anaphora. In this respect swój is similar to 'his/her own' in English since we have in English determiners like 'all his own' or 'ten of her own' etc. .

Thus in Polish one has compound determiners like wiekszość swoich... 'most HOWN', 10 swoich... '10 HOWN', żaden ze swoich... or żaden swój 'no HOWN', conajmniej 5 swoich... 'at least 5 HOWN', wszystkie swoje... oprócz Kazia 'every HOWN, except Kazio', etc. Some examples of such compound anaphoric determiners are given below:

(10) On lubi wszystkie swoje dzieci, oprócz Kazia. He likes all HOWN children, except Kazio

'He likes all his (own) children, except Kazio'

(11) On zna niektórych swoich sa̧siadów, włącznie z Kaziem. He knows some HOWN neighbours, including with Kazio

'He knows some his neighbours, including Kazio'

Such complex anaphoric determiners have a Boolean structure, and consequently one can form their various Boolean compounds using appropriate conjunctions. We have for instance większość ale nie wszystkie swoje... 'most but not all HOWN', 5 or 6 swoich... '5 or 6 HOWN', etc.

Observe that in the above examples the determiner swój, or some if its versions, does not occur in both Boolean compounding parts. In other words it is possible (but not necessary) to delete the anaphoric determiner from one of the conjuncts, the first or the second. Such a deletion rarely leads to the scope ambiguity. In case when there are more than two conjuncts, when the determiner is deleted it has to be deleted from all conjuncts but one.

In addition, in Polish, but apparently this is not the case in other Slavic languages, bare anaphoric determiners swój and the corresponding feminine, neuter and plural forms have the negative form nieswój/nieswoja/nieswoje 'not-HOWN'. One has to say that such negative forms are much better and more frequently formed with the plural anaphoric determiner swoje to form nieswoje. Here is an example of such a construction:

(12) On pomaga zwłaszcza nieswoim studentom.

He helps especially not-HOWN students

'He helps in particular other people's students.'

One should mention that in Polish, and in other Slavic languages, there is a lexical item $c u d z y / c u d z a / c u d z e$ 'not own, foreign' whose meaning seems equivalent to nieswój. There are interesting differences, however, between cudzy and nieswój. For instance cudzy can occur in noun phrases in subject position and in predicates. Furthermore, its use is more restricted since it seems to apply basically to animate or even human beings. 
The negative forms, that is negations of bare forms, can in turn combine with "ordinary" determiners or with compound determiners to give even more complex anaphoric determiners. Thus both bare, negative and positive, forms can occur in such complex anaphoric determiners. For instance we have in Polish niektóre nieswoje... 'some not-HOWN', 5 swoich i 6 nieswoich... '5 HOWN and 6 notHOWN' as in (4) and (5):

(13) Ona lubi 5 swoich i 6 nieswoich kotów.

She likes 5 HOWN and 6 not-HOWN cats

'She likes 5 cats of hers her and 6 others.'

(14) Ona lubi wszystkie swoje albo większość swoich kotów.

She likes all HOWN or most HOWN cats

'She likes all of her or most of her cats.'

Anaphoric determiners can also combine with "ordinary" possessive (nonanaphoric) determiners formed in Polish by the genitive case of the possessor noun. In that way, one obtains a somewhat different class of complex anaphoric possessive determiners. Thus one has swoje i Kazia... 'HOWN and K.'s', 5 swoich i 6 Kazia... ' 5 HOWN and 6 K.'s'. Here is an example of a sentence with such a determiner:

On spotkal 5 swoich i 6 Kazia studentów.

He met 5 HOWN and 6 Kazio's students

'He met 5 of his own and 6 of Kazio's students.'

The bare anaphoric determiner swój can also combine with "ordinary" binary (or even n-ary) determiners to give binary (or n-ary) anaphoric determiners. For instance, swój combined with the binary determiner wiecej...niz (more...then) gives the binary anaphoric determiner wiecej swoich... niz swoich.../more HOWN... than HOWN.... Similarly with reducible (by conjunction) n-ary determiners (such as for instance English All $A, B$, and..C read as All $A$ and All $B$ and... and All C). In Polish such determiners can combine with swój to give (Booleanly reducible) n-ary anaphoric determiners. Thus the way of making compound binary anaphoric determiners is even richer. Again, it is not necessary to repeat in such complex binary determiners swój in every "conjunct" though in some cases scope ambiguity can arise. Here are some examples:

a. Kazio sprzedał więcej swoich książek niż obrazów Kazio sold more HOWN books than paintings 'Kazio sold more of his (own) books than paintings'

b. Kazio sprzedał więcej swoich obrazów niż Piotr książek Kazio sold more HOWN paintings than Piotr books

'Kazio sold more of his own paintings than (his) books'

Complex anaphoric determiners share many properties with bare anaphoric determiners. Thus semantically they do not give rise to the sloppy identity ambiguity. The sentence in (17) is not ambiguous, unlike its English translation: its 
translation can mean either (18) or (19) whereas the Polish sentence (17) means only (18):

(17) Tylko Kazio nienawidzi swoje koty. Only Kazio hates HOWN cats

'Only Kazio hates his cats'

(18) Kazio is the only person such that that person hates his own cats.

(19) Kazio is the only person such that that person hates Kazio's cats.

In the next section we propose a semantics for anaphoric determiners which is compatible with many facts presented in this section.

\section{Semantics of anaphoric determiners}

The anaphoric determiners we analyse here are expressions which form anaphors (in fact, nominal anaphors), when applied to one or two common nouns. In English a typical nominal anaphora is given by the reflexive pronoun him/herself. Interestingly this pronoun can also be used with "ordinary" determiners (or their parts) complex anaphoric determiners in English. Using for instance the unary determiner every... except Bill we get the anaphoric determiner every...except himself. Similarly we have most...including herself. These anaphoric determiners form nominal anaphors when applied to a common noun: we have for instance every doctor except himself or most students including herself. So English also has complex anaphoric determiners. Their semantics is easy to provide given the semantics of "ordinary" determiners whose parts occur in them.

There are important differences between the English complex anaphoric determiners indicated above and the Slavic anaphoric determiners we analyse here. First, semantically, the English examples do not involve any possessive relation. We will see when discussing generalised conservativity, that this leads to some differences in the strength of conservativity between English and Slavic anaphoric functions. Second, from an empirical point of view, we have seen that in Polish swój can combine with virtually any unary and binary determiner. This is not the case in English determiners containing self.

In this section we analyse the possessive nature of Slavic anaphoric determiners. In the next section we approach the question of their anaphoricity and then the question of their conservativity.

In presenting the formal properties of Slavic anaphoric determiners the following notation will be used. The type of functions from binary relations to sets will be noted $\langle 2: 1\rangle$, the type of functions from sets and relations to sets will be noted $\langle 1,2: 1\rangle$ and the type of functions from two sets and a binary relation to sets will be noted $\langle 1,1,2: 1\rangle$. Furthermore, $a R$, where $a$ is an individual, element of the fixed universe $E$, and $R$ a binary relation, is a set defined as: $x R=\{y:\langle x, y\rangle \in R\}$. Thus $a R$ is the set of all objects to which $a$ is in the relation $R$. 
When a noun phrase occurs in subject position it takes a verb phrase as argument and gives a sentence. Semantically such noun phrases denote type $\langle 1\rangle$ quantifiers. They take a set (property) and give a truth value (proposition). However when the noun phrase occurs in object position it takes the transitive verb phrase and gives a full verb phrase. Semantically, in this case the quantifier denoted by the noun phrase takes a relation as argument and gives a set as a result. To account for this possibility one considers extensions of type $\langle 1\rangle$ quantifiers. Here we consider the accusative extension $Q_{a c c}$ of the quantifier $Q$. By definition: $Q_{a c c}(R)=\{x$ : $Q(x R)=1\}$. Thus, roughly, an (accusative) extension of a type $\langle 1\rangle$ quantifier is a function from relation to sets defined with the basic properties of this quantifier. It corresponds to the denotation of a verb phrase composed of a transitive verb and a direct object. In the next section we will see that noun phrases formed from anaphoric determiners are formally different from ordinary direct objects.

To account for the possessive character of anaphoric determiners in Polish we need in addition to introduce the binary relation POS which contextually expresses the abstract or generalised possessor relation (which needs not to be just "material" ownership or the authorship relation). Such a relation, contextually determined, is needed for the semantics of "ordinary" possessives as well (Peters and Westerståhl (2006)). Then obviously aPOS is the set of all objects which $a$ "owns" in this abstract sense.

Our goal now is to represent the possessive aspects of the semantics of simple and complex anaphoric determiners whose empirical properties we have seen. Concerning bare determiners, it is necessary to analyse separately the meaning of the singular and plural forms. The semantics of swoj in singular is simple if one supposes that the singular presupposes the unicity of the possessed object. Consider (20):

(20) Piotr podziwia swego sassiada

Piotr admires HOWN neighbour

'Piotr admires his neighbour'

On its most natural reading (20) entails (presupposes) that Piotr has just one neighbour. Formally we express such unicity of objects having a specific property using the description operator iota $\imath$. More specifically, the description noted $\imath x(x \in$ $A$ ) designates the unique object $x$ which has the property $A$, if such an object exists. With the help of this notation the semantics of bare singular swój can be represented as follows:

$\operatorname{SVOJ}(A, R)=\{x:|x P O S \cap A|=1 \wedge\langle x, \imath y(y \in x P O S \cap A)\rangle \in R\}$

It follows from (21) that (22) is true and thus that (20) entails (23): .

$\operatorname{SVOJ}(A, R) \subseteq \operatorname{SOME}(A)_{a c c}(R)$

(23) Piotr podziwia pewnego sa̧siada

Piotr admires some neighbour

'Piotr admires some neighbour' 
Interestingly, bare plural anaphoric determiners like swoje (used without a "normal determiner") are more complicated to analyse. Like many other possessives (or bare NPs) they are ambiguous and can have either existential or universal readings. The sentence Kazio nienawidzi swoje kochanki (K. hates his mistresses) does not imply that $\mathrm{K}$. hates all of his mistresses (though this is a strongly preferable reading). The ambiguity is even stronger with the plural form nieswoje:

Kazio lubi swoje i nieswoje koty.

Kazio likes HOWN and not-HOWN cats

'Kazio likes his and other people's cats'

There are important variations in readings of such constructions. It seems clear, for instance, that (24) does not entail that Kazio likes all cats. So a good approximation is to consider that bare anaphoric determiners contain in fact a hidden determiner corresponding to the quantifier ALL OR SOME. I will not treat this problem in any detail since, as far as I can tell, the same type of ambiguity between universal and existential readings also arrises in the semantics of bare noun phrases and in the semantics of "ordinary" possessive constructions. So a more general solution, applicable to all cases, is desirable.

Let us see now the semantics of complex Slavic anaphoric determiners. As we have seen such complex determiners are formed in Polish with swój (in singular or plural) and an "ordinary" determiner. The exact syntactic description of the way such a composition takes place will not matter here. Given a relatively free word order in Polish such a description is far from simple. Concerning the semantics of such complex determiners we want it to be a function of the semantics of the ordinary determiner which is the part of the complex anaphoric determiner.

Let $D$ be a type $\langle 1,1\rangle$ quantifier, the denotation of some unary determiner Det. $D_{S}$ is the denotation of the anaphoric determiner Det swój obtained by combining Det with swój according to the rules underlying the examples discussed in the previous section. We know that such a determiner applies to a common noun and gives a (usually accusative) nominal anaphora, in the sense of Keenan (Keenan (1988)). Nominal anaphors denote functions of type $\langle 2: 1\rangle$. Given this, $D_{S}$ a function of type $\langle 1,2: 1\rangle$. Then:

$$
D_{S}(A, R)=\{x: x P O S \cap A \neq \emptyset \wedge D(x P O S \cap A)(x R)=1\}
$$

The clause $x P O S \cap A \neq \emptyset$ expresses the existential presupposition that possessives induce. The remaining part shows how the anaphoricity is expressed by the accusative case extension of the type $\langle 1\rangle$ quantifier formed with $D$ applied to $A$ which is modified with the help of POS. Thus Kazio admires most of his students is true if $K$ is a member of the set $\{x: x P O S \cap S \neq \emptyset \wedge M O S T(x P O S \cap S)(x A)=1\}$, where $A$ is the relation corresponding to admire and $S$ the set of students..

It follows from (25) that (26) is true and thus that (27a) entails (27b):

$$
F I V E_{S}(A, R) \subseteq F I V E(A)_{a c c}(R)
$$


a. Jan spotkał 5 swoich studentów.

Jan met 5 HOWN students

'Jan met 5 (of) his students'

b. Jan spotkał 5 studentów.

Jan met 5 students

'Jan met 5 students'

The formula in (25) gives a semantics for complex anaphoric determiners containing the "positive" form of the determiner swój. For nieswój we have the following semantics:

$$
D_{N S}(A, R)=\{x: \exists y \neq x(y P O S \cap A \neq \emptyset) \wedge \forall y \neq x(D(y P O S \cap A)(x R)=1\}
$$

Notice that no difference is made between singular nieswój and its plural form nieswoje. My feeling is that, at least for some cases, such a difference does exist but it is not easy to grasp. In addition, observe that (28) does not entail the unicity of the possessed object. Indeed (29) does not entail that there is only one son whose father is someone other than Jan:

Jan bił nieswego syna
Jan was-hitting not-HOWN son

'Jan was hitting somebody else's son'

Concerning binary anaphoric determiners, we only indicate its representation which is given in (30):

$$
D_{B S}(X, Y, R)=\{a: a P O S \cap(X \cap Y) \neq \emptyset \wedge D(a P O S \cap X, a P O S \cap Y)=1\}
$$

$D_{B S}(X, Y, R)$ is a binary anaphoric function denoted by the binary anaphoric determiner associated with the "ordinary" binary determiner denoting $D$. It is of type $\langle 1,1,2: 1\rangle$.

\section{Anaphoricity}

What is interesting is the fact that NLs display other interpreting functions from binary relations to sets than accusative extensions of type $\langle 1\rangle$ quantifiers. The typical example is the function SELF defined as follows: $\operatorname{SELF}(R)=\{x:\langle x, x\rangle \in R\}$. This function interprets the reflexive him/herself in English. However, it is not an accusative extension of any type $\langle 1\rangle$ quantifier: for no type $\langle 1\rangle$ quantifier $Q$ is it true that $S E L F=Q_{a c c}$. Indeed, functions which are accusative extensions satisfy the accusative extension condition AEC given in (31), whereas functions like SELF satisfy the strictly weaker anaphoric condition AC (Keenan (2007)) given in (32):

(31) A function $F$ from binary relations to sets satisfies AEC iff for any binary relation $R$ and $S$ and any $a, b \in E$ if $a R=b S$ then $a \in F(R)$ iff $b \in F(S)$ 
(32) $\quad F$ (from binary relations to sets) satisfies AC iff for any $a \in E$, and $R$ and $S$ binary relations, if $a R=a S$, then $a \in F(R)$ iff $a \in F(S)$

The following simple condition can be used to decide whether functions from binary relations to sets to satisfy the AEC condition:

(33) If a function $F$ from binary relations to sets satisfies AEC, then for any $A \subseteq E$, one has $F(E \times A)=\emptyset$ or $F(E \times A)=E$.

Using the condition in (33) it is easy to show that the function SELF does not satisfy AEC. However, this function satisfies the AC condition given in (32). Obviously, functions which are accusative extensions of some quantifiers also satisfy AC. This means that anaphoric functions should not satisfy AEC:

A type $\langle 2: 1\rangle$ function is anaphoric iff it satisfies AC and fails AEC.

One can check (Keenan 2007) that $S E L F$ is an anaphoric function of type $\langle 2: 1\rangle$ as is the function NOBODY-EXCEPT-SELF.

The AC applies to functions of type $\langle 2: 1\rangle$. We need a similar condition for functions of type $\langle 1,2: 1\rangle$ and functions of type $\langle 1,1,2: 1\rangle$. For the first class of functions, we have the condition given in (35) and for the second, in (36):

ACD1: A function $F$ of type $\langle 1,2: 1\rangle$ satisfies the anaphor condition for unary determiners (ACD1) iff for any $a \in E, X \subseteq E$ and $R, S$ binary relations, if $a(E \times X \cap R)=a(E \times X \cap S)$, then $a \in F(X, R)$ iff $a \in F(X, S)$.

(36) ACD2: A function $F$ of type $\langle 1,1,2: 1\rangle$ satisfies the anaphor condition for binary determiners (ACD2) iff for any $a \in E, X, Y \subseteq E$ and $R, S$ binary relations, if $a(E \times X \cap R)=a(E \times X \cap S)$ and $a(E \times Y \cap R)=a(E \times Y \cap S)$ then $a \in F(X, Y, R)$ iff $a \in F(X, Y, S)$.

Conditions in (35) and (36) are just generalisations of the AC condition in the sense that functions satisfying ACD1 and ACD2 are those from which we get functions satisfying $\mathrm{AC}$ when fixing their set arguments.

We can use the same method of fixing nominal arguments to define anaphoric functions of type $\langle 1,2: 1\rangle$ and of type $\langle 1,1,2: 1\rangle$. Thus we have the following definitions:

A function $F$ of type $\langle 1,2: 1\rangle$ is anaphoric iff it satisfies the ACD1 condition and the function $G^{A}$ of type $\langle 2: 1\rangle$ defined as $G^{A}(R)=F(A, R)$ is anaphoric, in the sense of (34), for any non-trivial $A$.

(38) A function $F$ of type $\langle 1,1,2: 1\rangle$ is anaphoric iff it satisfies the ACD2 condition and the function $G^{A, B}$ of type $\langle 2: 1\rangle$ defined as $G^{A, B}(R)=F(A, B, R)$ is anaphoric for any non-trivial $A$ and $B$.

In the definitions above, anaphoricity of type $\langle 1,2: 1\rangle$ and type $\langle 1,1,2: 1\rangle$ functions is reduced to anaphoricity of type $\langle 2: 1\rangle$ functions defined in (32). The condition 
of non-triviality of $A$ and $B$ is necessary because for trivial values of $A$ or $B$ we get functions which also satisfy AEC.

The somewhat heavy machinery presented above was introduced in order to show that functions denoted by Slavic anaphoric determiners, unary and binary, are anaphoric functions. This can be done using the semantics indicated in (21) and (25) and the definitions of anaphoric functions given above.

\section{Conservativity}

Before looking at generalised conservativity applying to denotations of anaphoric determiners, let me mention an interesting formal difference between Slavic complex anaphoric determiners and English ones formed with self, indicated above. Functions denoted by English anaphoric determiners satisfy condition (i) in (39). Slavic anaphoric determiners do not satisfy this condition. If we suppose that the possessor relation $P O S$ is anti-reflexive, denotations of Slavic anaphoric determiners satisfy condition (ii) given in (39):
(i) $F(A, R) \subseteq A$,
(ii) $F(A, R) \subseteq\{x: x P O S \cap A\}^{\prime}$

Determiners in natural languages, or rather their denotations, universally satisfy the property of conservativity (even if this claim needs some comment; for some counterexamples to the claim concerning Polish, see Zuber (2004). This is true of unary as well as binary determiners, even if binary determiners may universally satisfy some additional constraints (Zuber (2009)). In the definition of conservativity, for denotations of unary (and binary as well) determiners, one uses explicitly the fact that one of the arguments of the corresponding quantifier is nominal, that is occurs in the noun phrase in the subject position. As we have seen, anaphoric noun phrases formed from anaphoric determiners cannot occur in the subject position and thus the classical definition of conservativity does not apply to them directly.

Observe, in addition, that anaphoric functions are not quantifiers, although those we consider are systematically related to quantifiers. One can generalize the notion of conservativity in that it also applies to functions like $D_{S}(A, R)$ above. Here is the corresponding definition and the proposition indicating an equivalent definition for such functions:

(40) Let $F$ be of type $\langle 1,2: 1\rangle$. Then $F$ is conservative iff for all $X \subseteq E$ and $R_{1}, R_{2}$ binary relations, if $E \times X \cap R_{1}=E \times X \cap R_{2}$ then $F\left(X, R_{1}\right)=F\left(X, R_{2}\right)$.

(41) A function $F$ of type $\langle 1,2: 1\rangle$ is conservative iff $F(X, R)=F(X, E \times X \cap R)$

One can check now that the function SVOJ defined in (22) is conservative. Concerning the complex (unary) anaphoric determiner formed with the determiner swój (which denotes function $D_{S}$ defined above), we have the following general result: 
(42) If a type $\langle 1,1\rangle$ quantifier $D$ is conservative, then function $D_{S}$ is conservative (where $\left.D_{S}(A, R)=\{x: x P O S \cap A \neq \emptyset \wedge D(x P O S \cap A)(x R)=1\}\right)$.

Consequently, Slavic complex anaphoric determiners denote conservative functions $D_{S}$ if the ordinary determiner with which they are composed denotes a conservative quantifier $D$. When the compounding determiner $D$ is not conservative, the "Slavic" complex anaphoric determiner to which it gives rise may denote a non- conservative type $\langle 1,2: 1\rangle$ function. Consider the example in (43):

Leo podziwia tylko swoich studentów.

Leo admires only HOWN students

'Leo admires only his (own) students'

The sentence in Polish as well as its English translation is probably ambiguous: depending on whether the focus is on emphonly or on own, it can mean that either Leo admires his own students and nothing else or that Leo admires his own students and not other students. Thus the following two type $\langle 1,2: 1\rangle$ functions are involved in the semantics of (43):

(i) $F(A, R)=\{x: x R \subseteq x P O S \cap A\}$, (ii) $F(A, R)=\{x: x R \cap A \subseteq x P O S \cap A\}$

One can check that the function in (ii) is conservative and the one in (i) is not.

Interestingly, it is not obvious that tylko 'only' in (42) is a determiner. In fact in Polish there is a series of non-conservative determiners which, though related semantically to tylko are different from it, they should be expressed by sami, with possibly an additional inclusion clause (Zuber 2004). However sami cannot be used in (43).

Let us now come back to the difference between English and Slavic anaphoric determiners mentioned in (39). Both types of determiners denote type $\langle 1,2: 1\rangle$ anaphoric functions which satisfy condition ACD1. It follows from this in conjunction with the property (i) in (39) that "English anaphoric functions" satisfy in addition the following version of "anaphoric" conservativity:

A type $\langle 1,2: 1\rangle$ function $F$ is A-conservative iff $F(X . R)=F(X, X \times X \cap R)$

This version of conservativity is not satisfied by "Slavic anaphoric functions".

Given that binary anaphoric determiners cannot occur in noun phrases occurring in subject position we also need to generalise the notion of conservativity to type $\langle 1,1,2: 1\rangle$ functions. Here is the corresponding definition:

(46) A type $\langle 1,1,2: 1\rangle$ function $F$ is conservative iff for any $X_{1}, X_{2} \subseteq E$ and any binary relations $R_{1}$ and $R_{2}$, if $E \times X_{1} \cap R_{1}=E \times X_{1} \cap R_{2}$ and $E \times X_{2} \cap R_{1}=$ $E \times X_{2} \cap R_{2}$, then $F\left(X_{1}, X_{2}, R_{1}\right)=F\left(X_{1}, X_{2}, R_{2}\right)$.

Thus, roughly, in order to judge the truth of sentences with anaphors formed with binary anaphoric determiners it is enough to consider a domain of the relation denoted by the transitive verb restricted to the union of the two arguments of the binary determiner. One can check that anaphoric functions defined in (30) denoted by complex Slavic binary anaphoric determiners are conservative in the above sense. 


\section{Conclusive remarks}

Results presented above should in many respects be considered as preliminary. Let me mention some points which have not been sufficiently, or not at all, touched upon.

First, though many data, sometimes less well known, have been presented, the relationship between the data provided and the theoretical proposals which have been suggested has not been made clear. In particular, it is not clear how the semantics which has been proposed is related to various constraints underlying the empirical facts which have been presented. Similarly, it is not clear what the logical relationship between a determiner with the positive form of swój and the corresponding determiner with the negative form is.

More importantly, the semantic proposal made above makes essential use of type $\langle 1,2: 1\rangle$ and type $\langle 1,1,2: 1\rangle$ functions. This means that some specific semantic types are introduced. The general methodology of linguistic semantics requires that the introduction of a new semantic type should be justified. This is not what has been done here.

Finally, the analysis of the possessive nature of Slavic anaphoric determiners cannot be separated from the analysis of possessive constructions in general. Though we adopted the proposal made in Peters and Westerståhl (2006), more should be said about the POS relation. We have seen that some formal properties of anaphoric functions depend on properties of POS. We have suggested that it should be anti-reflexive in the sense that no individual is in POS relation with itself. Since, as example (7) above shows, many anaphoric determiners can occur in the same sentence, a very abstract definition of the POS relation is needed.

\section{References}

Keenan, E. L.: 1988, 'On Semantics and the Binding Theory', in J. Hawkins (ed.), Explaining Language Universals, 105-144. Blackwell.

Keenan, E. L.: 2007, 'On the Denotations of Anaphors', Research on Language and Computation 5, 5-17.

Peters, S. and D Westerståhl: 2006, Quantifiers in Language and Logic. Oxford U.P.

Zuber, R.: 2004, 'A class of non-conservative determiners in Polish', Linguisticae Investigationes 27, 147-165.

Zuber, R.: 2009, 'A semantic constraint on binary determiners', Linguistics and Philosophy 32, 95-114. 